\title{
CAREERS
}

UNITED STATES Fellowship supports international graduate students. p.363
EDUCATION Number of physics PhDs on the rise in the United States. p.363
NATUREJOBS For the latest career listings and advice www.naturejobs.com

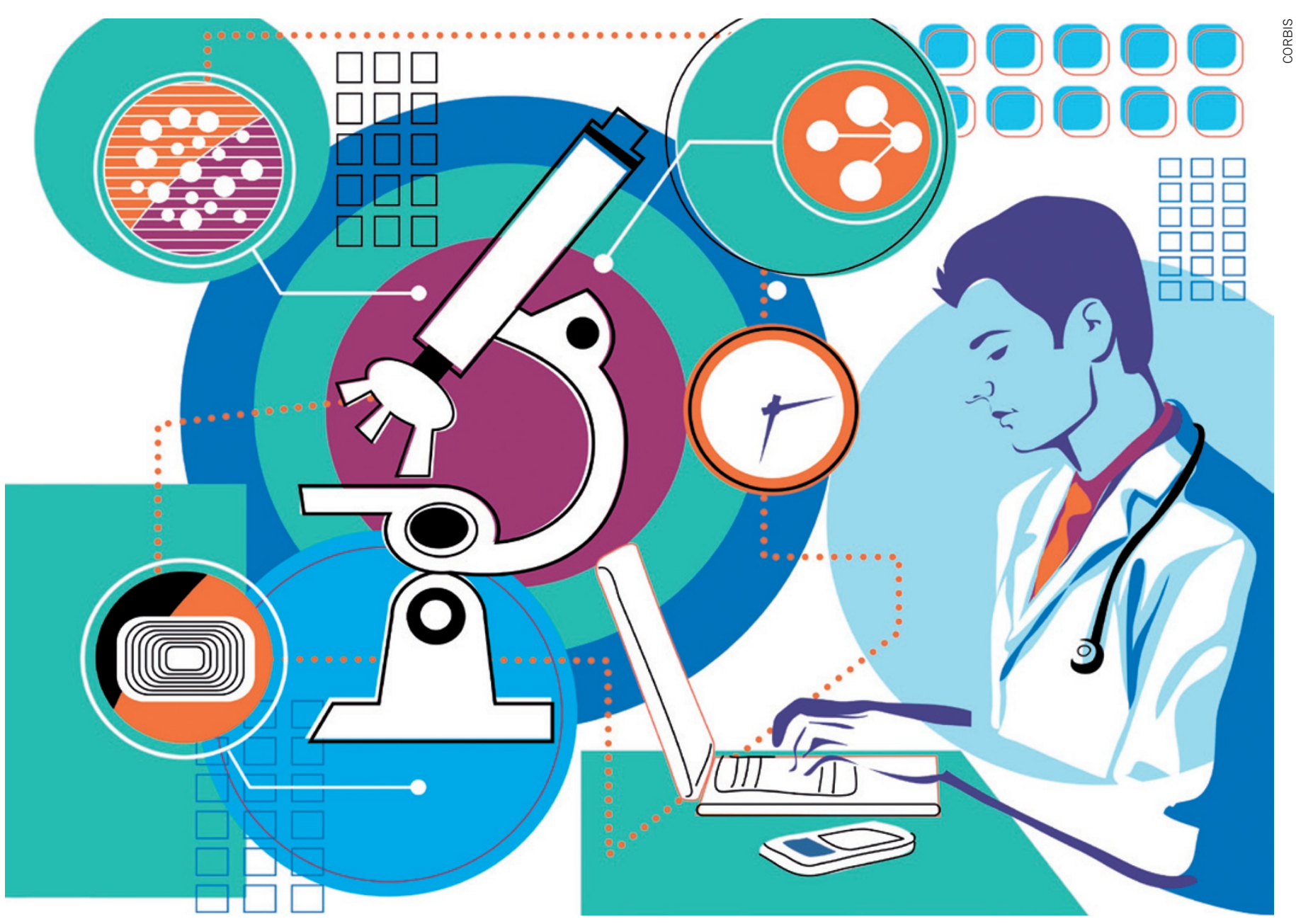

CLINICAL SCIENCE

\section{Research and repair}

\section{Maintaining a research focus is among the challenges facing aspiring physician-scientists.}

\section{BY JEFFREY PERKEL}

$\mathrm{F}$

or every day that Thomas Cappola spends tending to patients, he spends four in his - lab, trying to understand at the genetic level why those patients are ill, and how they can best be treated. To do so, Cappola, a cardiologist at the University of Pennsylvania School of Medicine in Philadelphia, relies not only on his extensive medical training, but also on a postdoctoral fellowship in applied genomics.

Cappola is a physician-scientist - a scientifically trained clinician who works in both patient care and research, in this case applying genomics technology, bioinformatics and statistics to his heart-failure patients' blood and DNA samples. Cappola likes to say that he has a "crazy set of skills", which he enjoys using. "I see patients one day a week, and the rest of the time I get to think about their problems and how to solve them," he says.

In a sense, physician-scientists are like any other scientist competing for the jobs, funding and personnel required to advance their research. Yet theirs is a profession with its own hurdles and opportunities, and one to which funding agencies are paying special attention, especially with taxpayers demanding proof that federal grants are being put to good use.

The career path isn't easy. It requires a diverse set of research and people skills, and a willingness to endure long hours, intensive schooling and, frequently, multiple degree programmes. But those who secure degrees and physician-scientist posts may find it easier to get jobs than do most people with $\mathrm{PhDs}$ in the life sciences. 
> Physician-scientists can also boast a satisfying vocation that combines curiosity-driven research with a patient-focused approach. Aspirants should beware, however: in some quarters, an emphasis on translational research, stemming in part from economic realities, has forced physician-scientists to spend more time in the clinic than they might have in the past.

\section{LONG AND EXPENSIVE}

No hard numbers on career prospects exist, but anecdotal evidence suggests that physician-scientists compete well with their PhD-holding peers. In part, that is because the physicianscientist pool, at least in the United States, has been contracting and ageing for years, says Andrew Schafer, chairman of the department of medicine at Weill Cornell Medical College in New York and editor of The Vanishing Physician-Scientist? (ILR, 2010).

"There's no question that there is a critical situation," says Schafer. "The disappearance of physicianscientists threatens the very essence of what we call translational research, because if not for them, who would be left to translate anything?" As a result, he says, job prospects in general are good. "Virtually every major academic medical centre wants physician-scientists," says Schafer.

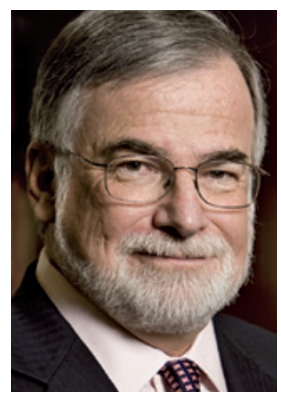

"Virtually every major academic medical centre wants physicianscientists."

However, there are Andrew Schafer myriad barriers to establishing oneself as a physician-scientist. First, it can require a long stint at university. For example, the bachelor of medicine (MB)/ $\mathrm{PhD}$ programme at University College London (UCL) follows a $0.5-3-2$ format - after an undergraduate degree that includes preclinical coursework, the student undertakes half a year of postgraduate clinical training, then 2.5-3.5 years of research and another two years of clinical work. By contrast, US combined MD-PhD programmes, initiated after completion of an undergraduate non-clinical programme, typically take 8 years in a 2-4-2 format: two years of preclinical coursework, four of research and two of clinical training.

For those who do not receive funding as part of their MD-PhD programmes (which, at least in the United States, are tuition-free and include a stipend), university can be expensive. US physicians who want to focus on research must often deal with a mountain of debt as they pursue further studies or a research postdoc. According to a 2010 survey $^{1}$ by the Association of American Medical Colleges (AAMC) in Washington DC, the average indebted medical student owes nearly US $\$ 160,000$ at graduation. Many are therefore eager to get into a practice and start paying off their loans. "The vast majority of MDs have so much debt they cannot afford to do research unless they are either independently wealthy or are very, very motivated," says Ajit Varki, a biomedical scientist at the University of California, San Diego, and former associate dean of the university's physician-scientist training programme.

The US National Institutes of Health (NIH) has a loan-repayment programme (LRP) that helps to defray some costs for physicians who decide to move into research, paying back up

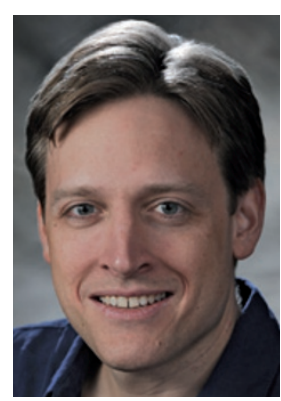

"I get to see patients one day a week and the rest of the time I get to think about their problems and how to solve them."

Thomas Cappola to $\$ 35,000$ of debt per year on the recipient's behalf. Cappola used

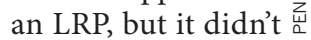
cover the entire balance of his debt. "I am debt-free now," he says, "but it took time and not just the LRP. It took a lot of work."

UCL's $\mathrm{MB} / \mathrm{PhD}$ programme is tuitionfree for the research period, but there are charges for the clinical training. Still, says Gordon Stewart, programme tutor at UCL, the cost is much lower than that of straight US medical degrees; UK medical students typically graduate with $£ 15,000-40,000$ (US\$24,000-65,000) of debt, he says. "The loans are not nearly as big as they have to take out in the United States, but the salaries they get at the end of the day are nothing like as big as they get in the United States, either," he says.

Once they get past university, physicianscientists must survive not only the transition from postdoc to faculty member, but also the initial phases of their first posts, as they try to establish self-perpetuating research programmes. This entails an ongoing battle over the pressure to work in the clinic. Most physician-scientists have to cover their salary costs - the patient hours that must be billed to match the cost of their salary. Granting agencies have attempted to support physician-scientists through several different funding mechanisms,

\section{GRANT OPPORTUNITIES}

\section{Mechanisms of support}

There is plenty of interest in fostering physician-scientists, and many funding possibilities. In the United States, for example, the National Institutes of Health (NIH) offers awards known as $\mathrm{K}$ grants, some of which fund budding physician-scientists. Awarded separately by each $\mathrm{NIH}$ institute, the schemes support licensed clinicians, dentists or veterinarians in basic (the K08 grant) or clinical (K23) mentored research projects, requiring the recipient to spend at least $75 \%$ of their time on research, during the difficult period between completion of their research training as a postdoc and the acquisition of principal-investigator grants.

For earlier-stage training, the Howard Hughes Medical Institute (HHMI), based in Chevy Chase, Maryland, offers oneyear fellowships at either a host university or the $\mathrm{NIH}$, called the Medical Research Fellows Program and the HHMI-NIH Research Scholars Program, respectively, to give medical, dental and veterinary students a chance to try their hand at research.

In the United Kingdom, Intermediate and Senior Clinical Fellowships from the Londonbased Wellcome Trust support physician-scientists during $\mathrm{PhD}$ education, postdoctoral training and as principal investigators. Cancer Research UK, also based in London, offers postdoc and senior fellowships to protect research time. The charity awarded five four-year Clinician Scientist Fellowships in 2011, each supporting the researcher's salary, a research assistant and supplies; the Senior Cancer Fellowship supports salary, two postdocs, a technician, a graduate student and consumables for six years.

Kathleen Cook Suozzi, a physician-scientist-in-training, says that her HHMI fellowship experience helped her to see how practicing physician-scientists manage their double lives, in part through conferences organized by the institute. "The spectrum upon which people split their time is pretty vast," says Cook Suozzi, a fourth-year medical student at New York University School of Medicine, who spent a year in a lab at Rockefeller University in New York. "I met physicians who spend $99 \%$ of their time in the lab, and I met surgical oncologists with a lab who are in the operating room $80 \%$ of the time. So we could see that you can make it work in a variety of ways and make it fit your needs." J.P. 
available to early-career scientists as well as seasoned practitioners (see 'Mechanisms of support'). But if they fail to win such grants, physician-scientists can be required to fall back on their medical training to see more patients, thereby diminishing their time in the lab. Down-on-their-luck physician-scientists can thus become progressively less competitive in research.

\section{TOUGH TRANSITION}

Supporting both research and clinical priorities is not easy, as Melina Kibbe, a vascular surgeon at Northwestern University in Chicago, Illinois, found out. Kibbe started her career using a K08 grant from the National Heart, Lung, and Blood Institute (NHLBI) in Bethesda, Maryland. She spends two days a week working in the operating theatre; for the remaining three days she runs a lab focused on the interaction of vascular implants with the body, and the development of therapeutic materials. Her grant required that she spend at least $75 \%$ of her time on research, yet provided only $\$ 75,000$ in salary support - not nearly enough to cover three-quarters of a year of surgeon's pay at a university hospital, which often far exceeds $\$ 100,000$. "Who is going to come up with the rest of the salary?" she asks. Kibbe was lucky; she managed to win a matching grant from the Society for Vascular Surgery in Chicago to cover the cost inequities between the NHLBI grant cap and her salary. "The matching grants make all the difference in the world," she says. Grant salaries vary across NIH institutes. Although NHLBI caps its grantees' pay at $\$ 75,000$, others allow salaries up to the current legislative cap of $\$ 199,700$. A spokesperson for the NIH office of extramural research says that the physician's institution is expected to supplement the awardee's salary as an "important indication of its commitment to the development of the physician-scientist's career".

It takes real commitment and great mentoring and support to resist the pressures to spend too much time in the clinic, says Nancy Andrews, dean of the Duke University School of Medicine in Durham, North Carolina, and former head of the MD-PhD programme at Harvard University and the Massachusetts Institute of Technology in Cambridge.

Women, especially, seem vulnerable during early-career transitions, says Schafer. Although they represent a growing fraction of the MD-PhD pool, they are less likely than men to remain physician-scientists, possibly owing to a lack of role models, or to a perception that such a career is incompatible with having children. "Unless major changes occur in academe to make research careers more attractive to women physicians, the overall pool of competitive physician-scientist prospects will continue to decline in the job market," he says.

Physician-scientists have historically been

in high demand, and that demand should continue, says Schafer. A 2007 AAMC survey $^{2}$ suggests that there are plenty of open positions for physician clinical investigators, with a little more than half of all departments surveyed unable to fill all their positions, and a quarter of positions overall going unfilled. According to Lawrence Brass, director of the Medical Scientist Training Program at the University of Pennsylvania, only about 550 students enter MD-PhD programmes in the United States each year. "That's not enough to sustain the number of physicianscientists working now, let alone expand it," he says. Although this is bad news for medical schools and research universities, it could be good for soon-to-be physician-scientists, who will find themselves very employable once they graduate.

Yet economic realities are adding new

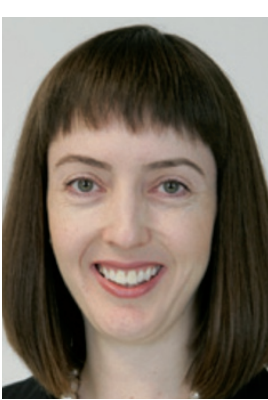

"The matching grants make all the difference in the world." Melina Kibbe port people doing research and not clinical work," says Steven Gabbe, chief executive of the Ohio State University Medical Center in Columbus, and former chair of the AAMC's Clinical Research Task Force II, which authored a report on promoting translational and clinical science ${ }^{3}$.

Still, says Gabbe, there will "always be a place for the creative, well-trained physicianscientist to find a faculty position". And for those who secure such positions, the rewards can be substantial. "As a physician-scientist, you really get to craft your career, if you are thoughtful about it," says Brass. "I get to discover new things, take care of patients with problems that interest me, and work with students who are eager and bright. That sounds like a great job description, doesn't it?"

Jeffrey Perkel is a freelance writer based in Pocatello, Idaho.

1. Association of American Medical Colleges 2010 GQ Medical School Graduation Questionnaire, All Schools Summary Report FINAL (AAMC, 2010). Available at go.nature.com/tyer27

2. Fang, D. et al. Recruitment of New Physician Investigators in Clinical Research (AAMC, 2007).

3. Task Force II on Clinical Research Promoting Translational and Clinical Science (AAMC, 2006).

\section{UNITED STATES}

\section{International funding}

A graduate fellowship will fund 48 international doctoral students in the United States and is seeking another 50 awardees in early September. Recognizing that graduate students from abroad often have trouble securing funding, the Howard Hughes Medical Institute (HHMI) in Chevy Chase, Maryland, established the programme, an annual US $\$ 2$-million commitment, this year. The fellowship provides $\$ 43,000$ a year for science and engineering $\mathrm{PhD}$ students in their third, fourth and fifth years of graduate school. Candidates, who must demonstrate creativity and innovation, are nominated by their institution. "We're looking for superstars," says Maryrose Franko, HHMI senior programme officer for graduate science education. "We expect these people will become scientific leaders."

\section{ITALIAN ACADEMIA}

\section{What's in a name?}

Nepotism is a widespread problem in Italian academic institutions, according to a statistical analysis of professors' last names. The study - which examined a database of more than 61,000 tenured professors from 94 institutions across 370 subdisciplines - found that the diversity of last names was lower than would be expected from unbiased hirings (S. Allesina PLoS ONE 6, e21160; 2011). Study author Stefano Allesina, an Italian ecologist at the University of Chicago in Illinois, says the index probably underestimates the incidence of nepotism because it identifies the problem only in father-child and sibling relationships. Allesina says he accounted for unrelated people with the same last names.

\section{EDUCATION}

\section{Upward physics trend}

Physics PhDs conferred by US institutions rose $38 \%$ between 2004 and 2008, the sharpest upswing in more than a decade, according to the latest survey data released by the American Institute of Physics in College Park, Maryland. Patrick Mulvey, lead research associate for the institute's statistical research centre, says the increase corresponds to a rise in enrolments in the early 2000s that was driven by an uncertain international economy and by improvements in the undergraduate culture of physics departments. Preliminary PhD totals for 2009 and 2010 show a similar trend, Mulvey says. 